\title{
730-nm-emitting Al-free active-region diode lasers with compressively strained InGaAsP quantum wells
}

\author{
A. Al-Muhanna, ${ }^{\text {a) }}$ J. K. Wade, and L. J. Mawst \\ Reed Center for Photonics, University of Wisconsin-Madison, Madison, Wisconsin 53706 \\ R. J. Fu \\ Applied Optronics Corporation, South Plainfield, New Jersey 07080
}

(Received 17 October 1997; accepted for publication 8 December 1997)

0.73 - $\mu$ m-emitting, Al-free active-region, strained $(\Delta a / a \approx 1.4 \%)$ InGaAsP single-quantum-well diode lasers have been grown by low-pressure metal-organic chemical-vapor deposition. A broad waveguide laser design with $\operatorname{In}_{0.5}\left(\mathrm{Ga}_{0.5} \mathrm{Al}_{0.5}\right)_{0.5} \mathrm{P}$ cladding layers is utilized to achieve a large effective transverse spot size $(d / \Gamma=0.433 \mu \mathrm{m})$ and to minimize carrier leakage from the active region. Threshold current densities of $514 \mathrm{~A} / \mathrm{cm}^{2}(100-\mu \mathrm{m}$-wide stripe, $L=1 \mathrm{~mm})$, external differential quantum efficiencies of $60 \%$, and characteristic temperature coefficients for the threshold current, $T_{0}$, and external differential quantum efficiency characteristic temperature, $T_{1}$, have values of 72 and $153 \mathrm{~K}$, respectively. Continuous wave output powers of $1.4 \mathrm{~W}$ are obtained from facet-coated $(90 \% / 10 \%)$ devices operating at $735 \mathrm{~nm}$. () 1998 American Institute of Physics. [S0003-6951(98)01306-0]

High output power diode lasers with wavelengths in the $730-780 \mathrm{~nm}$ range are needed for a variety of applications ranging from laser printing and optical recording to cancer treatments such as photodynamic therapy. For wavelengths less than $840 \mathrm{~nm}$, typical laser structures use AlGaAs in the active region, which can result in long-term reliability problems. As the emission wavelength decreases less than 780 $\mathrm{nm}$, the high aluminum content of the $\mathrm{Al}_{x} \mathrm{Ga}_{1-x} \mathrm{As}$ active layer $(x>0.1)$ makes reliable high-power operation increasingly difficult to achieve. Using a specially processed oxygen gettered aluminum source for the metal-organic chemicalvapor deposition (MOCVD) growth process, AlGaAs activelayer devices $(100-\mu \mathrm{m}$-wide emission aperture) have been reported with continuous wave $(\mathrm{cw})$ output powers of 540 $\mathrm{mW}$ at an emission wavelength of $715 \mathrm{~nm} .{ }^{1}$ More recently, compressively strained AlGaInAs active-layer lasers have been reported in the 730-nm wavelength range demonstrating $2.2-\mathrm{W} \mathrm{cw}$ output powers from broad-stripe $(100-\mu \mathrm{m}-$ wide) devices. ${ }^{2}$ Although high output powers have been obtained from the $\mathrm{AlGa}(\mathrm{In}) \mathrm{As}$ active-layer devices, ${ }^{1,2}$ longterm reliability is still an open question.

The use of an InGaAsP active-region offers an attractive alternative to conventional AlGaAs-based structures for short-wavelength, high-power sources. The lower surface recombination velocity of InGaAsP compared with AlGaAs leads to a dramatic reduction in facet-temperature rise during high-power cw operation. ${ }^{3}$ In fact, $\mathrm{Al}$-free active-region lasers in the 800-nm-wavelength region have recently demonstrated catastrophic optical mirror damage (COMD) at an internal power density, $\bar{P}_{\mathrm{COMD}}$, of $17.5 \mathrm{MW} / \mathrm{cm}^{2}$, which is more than twice the value reported for AlGaAs active devices at the same wavelength. ${ }^{4}$ Another advantage of using an InGaAsP-based active region is the ability to employ a strained-layer or strain-compensated quantum-well active re-

a)Electronic mail: al-muhan@cae.wisc.edu gion. Tensile-strained (In) GaAsP active-layer lasers have been reported operating in the 700-800 $\mathrm{nm}$ wavelength range. ${ }^{5}$ However, little is known about the properties of compressively strained quantum-well lasers in this wavelength region. The advantages of using compressively strained active layers, for both InGaAs and InGaAsP quantum-well lasers with emission at $980 \mathrm{~nm},{ }^{6} 1.3 \mu \mathrm{m},{ }^{7}$ and $1.55 \mu \mathrm{m},{ }^{8}$ has been well established. Similar improvements in performance (i.e., lower transparency current and higher differential gain) can be expected from incorporating compressive strain into InGaAsP quantum wells for laser emission in the 730-780 nm range.

Lasers structures have been grown by low-pressure metal-organic chemical-vapor deposition (LP-MOCVD), as described previously. ${ }^{9}$ Results are reported here for structures grown on (100) GaAs substrates misoriented $0.5^{\circ}$ towards $\langle 110\rangle$. The laser structure shown in Fig. 1 uses a $15-$ nm-thick compressively strained InGaAsP $(\Delta a / a \approx 1.4 \%)$ quantum well surrounded by $\operatorname{In}_{0.5} \mathrm{Ga}_{0.5} \mathrm{P}(200 \AA)$ transitional layers. Under these growth conditions, we find the InGaP to be partially ordered $\left(E_{g}=1.87 \mathrm{eV}\right)$. Since the InGaAsP/

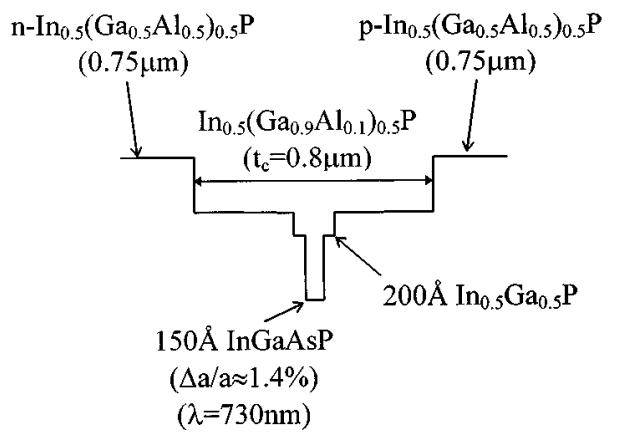

FIG. 1. Schematic diagram of Al-free active-region 730-nm-laser structure with broad-waveguide design. 


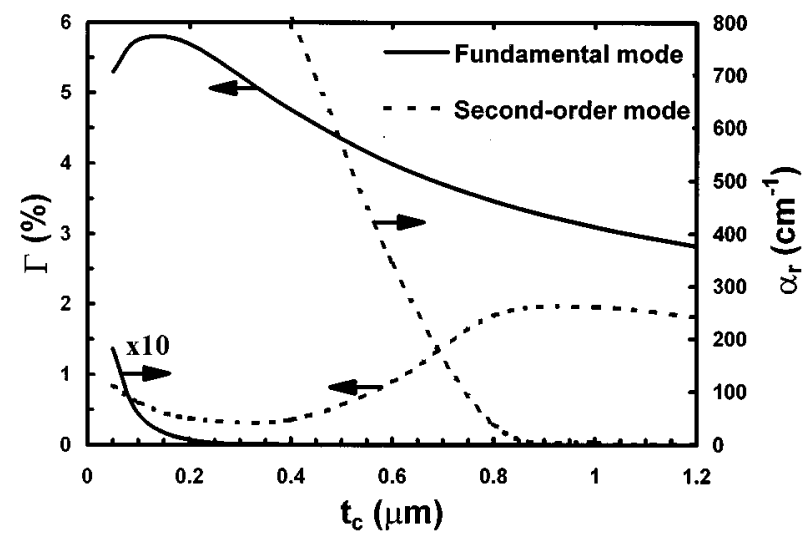

FIG. 2. Calculated optical confinement factor, $\Gamma$, and radiation losses, $\alpha_{r}$, for both fundamental and second-order transverse modes vs waveguide width, $t_{c}$. A value of $t_{c}=0.8 \mu \mathrm{m}$ results in a large effective transverse spot size $(d / \Gamma=0.433 \mu \mathrm{m})$, and maintains adequate discrimination against the second-order transverse mode.

GaAs material system has small band-gap differences, massive carrier leakage from the active region has been the major impediment to reach COMD in (completely) Al-free laser structures in the 800-nm-wavelength region. ${ }^{10,11}$ The use of high-band-gap Al-containing cladding layers has been shown to be effective in reducing carrier leakage in similar broad waveguide structures, incorporating a lattice-matched InGaAsP quantum well, emitting at $810 \mathrm{~nm} .{ }^{12}$ Therefore, $\mathrm{In}_{0.5}\left(\mathrm{Ga}_{0.5} \mathrm{Al}_{0.5}\right)_{0.5} \mathrm{P}(0.75 \mu \mathrm{m})$ cladding layers were employed to reduce carrier leakage. As the wavelength is shortened towards $730 \mathrm{~nm}$, carrier leakage becomes more severe, degrading device performance even further. For this reason, high-band-gap $\operatorname{In}_{0.5}\left(\mathrm{Ga}_{0.9} \mathrm{Al}_{0.1}\right)_{0.5} \mathrm{P}$ material $(0.8 \mu \mathrm{m})$ has been utilized in the structures reported here to reduce activeregion carrier leakage into the confining layers.

To measure the amount of strain in the quantum well, we grew three $75 \AA$ quantum wells separated by $1000 \AA \mathrm{GaAs}$ layers under the same conditions as the laser structure. Double-crystal x-ray diffraction measurements were performed and compared with simulated rocking curves confirming the amount of strain, $\Delta a / a$, in the InGaAsP quantum well is in the range $\Delta a / a=1.4 \%-1.6 \%$.

To achieve high output powers, a broad-waveguide design is employed. Design curves for the broad-waveguide structure are shown in Fig. 2, which includes optical confinement factors, $\Gamma$, and radiation losses to the GaAs $p^{+}$cap and underlying substrate, $\alpha_{r}$, for both fundamental and secondorder modes. Data for the first-order mode is not shown because its overlap with the quantum well is small (i.e., $\Gamma_{1}$ $=0)$. As the $\operatorname{In}_{0.5}\left(\mathrm{Ga}_{0.9} \mathrm{Al}_{0.1}\right)_{0.5} \mathrm{P}$ waveguide width, $t_{c}$, increases, the active-layer optical confinement factor, $\Gamma$, decreases from the optimal value, $t_{c}=0.1 \mu \mathrm{m}$, for achieving the lowest threshold current. Although the lowest possible threshold current density is not obtained for large $t_{c}$ values, a large equivalent transverse spot size, $d / \Gamma$, is achieved. However, from our experience, excessive increase in the waveguide width, $t_{c}>1 \mu \mathrm{m}$, results in multimode operation at high output powers despite the difference between $\Gamma_{0}$ and $\Gamma_{2}$, which results in a relatively small increase in threshold current for the second-order mode, $J_{\mathrm{th} 2} / J_{\mathrm{th} 0}=1.9$. To increase discrimination, we employ thinner confinement layDownloaded 24 Apr 2007 to 128.104.198.190. Redistribution subje

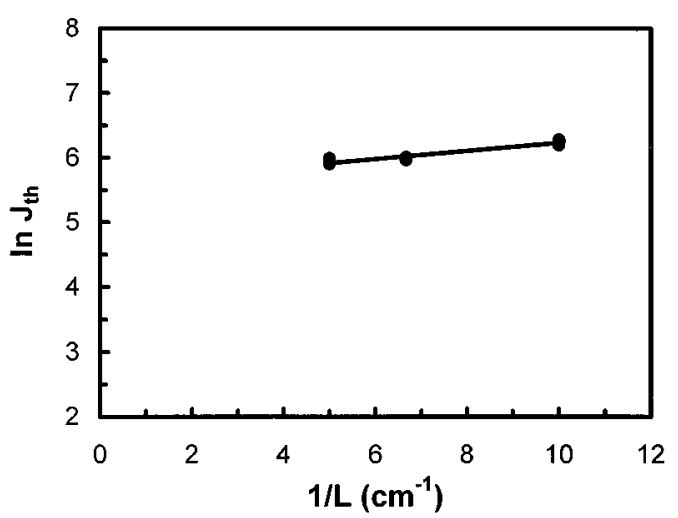

(a)

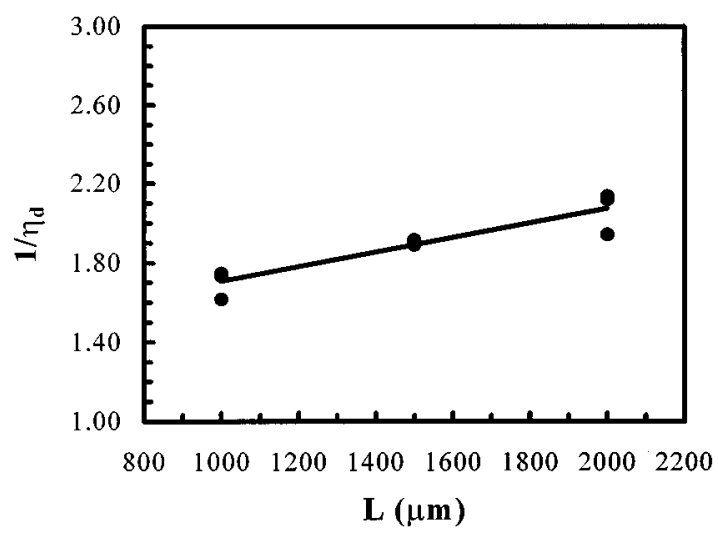

(b)

FIG. 3. Measured length dependence of threshold current density, $J_{\text {th }}$, and external differential quantum efficiency, $\eta_{d}$, as a function of device cavity length, $L$. (a) Fitted curve for logarithmic threshold current density, $J_{\text {th }}$, vs $1 / L$. (b) Inverse of external differential quantum efficiency, $1 / \eta_{d}$, as function of device length, $L$.

ers, $t_{c}=0.8 \mu \mathrm{m}$, such that $\alpha_{r 2} \gg \alpha_{r 0}, \quad \alpha_{r 2}=39.16 \mathrm{~cm}^{-1}$, $\alpha_{r 0}=0.012 \mathrm{~cm}^{-1}$, resulting in $J_{\mathrm{th} 2} / J_{\mathrm{th} 0}=6.8$, which as shown here is large enough to suppress the second-order mode. Accordingly, we obtain reasonable large equivalent transverse spot size, $d / \Gamma=0.433 \mu \mathrm{m}$, while maintaining single transverse-mode operation.

Broad-area (100- $\mu \mathrm{m}$-wide) lasers have been fabricated and characterized as a function of cavity length under lowduty-cycle pulsed current operation. Figure 3 shows the variation of the threshold current density, $J_{\text {th }}$, and external differential quantum efficiency, $\eta_{d}$, with device length, $L$. $J_{\text {th }}$ for $1-\mathrm{mm}$-long devices is $514 \mathrm{~A} / \mathrm{cm}^{2}$. Using published relationships ${ }^{13}$ between threshold current density, $J_{\text {th }}$, transparency current density, $J_{T}$, and gain saturation parameter, $G_{0}$, we calculated $J_{T}=173 \mathrm{~A} / \mathrm{cm}^{2}$ and $G_{0}=549 \mathrm{~cm}^{-1}$. As a result of the use of a broad waveguide, low internal loss is achieved $\left(\alpha_{i}=3 \mathrm{~cm}^{-1}, \eta_{i}=75 \%\right)$ because the field interaction with the highly doped cladding layers is minimal. $J_{\text {th }}$ and $\eta_{d}$ were measured as a function of temperature from 20 to $60{ }^{\circ} \mathrm{C}$. A best-fit analysis gives characteristic temperature coefficients of threshold current, $T_{0}$, and external differential quantum efficiency characteristic temperature, $T_{1}$, values of 72 and $153 \mathrm{~K}$, respectively. The relatively high values obtained for $T_{0}$ and $T_{1}$, compared with those published for to AIP license or copyright, see http://apl.aip.org/apl/copyright.jsp 


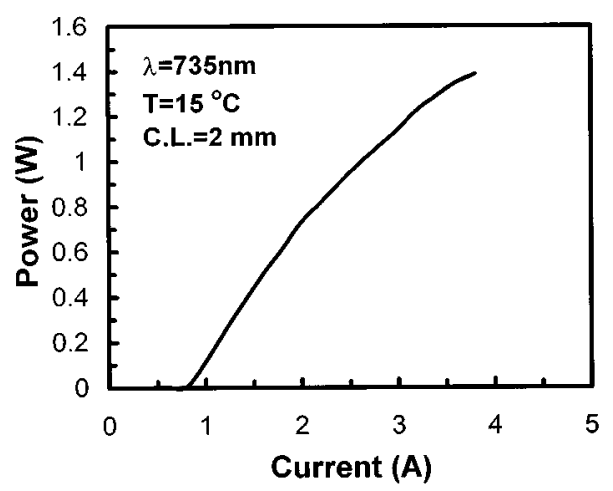

FIG. 4. Cw $L-I$ characteristics for $(90 \% / 10 \%)$ facet-coated $730-n m-$ emitting quantum-well $(100 \mu \mathrm{m} \times 2 \mathrm{~mm})$ laser.

AlInGaAs active-layer devices ${ }^{2} T_{0}=37 \mathrm{~K}$ and $T_{1}=63 \mathrm{~K}$, reflect the strong carrier confinement resulting from the use of $\mathrm{In}_{0.5}\left(\mathrm{Ga}_{0.5} \mathrm{Al}_{0.5}\right)_{0.5} \mathrm{P}$ cladding layers. For $\mathrm{cw}$ measurements, devices are mounted junction-side down on copper submount and the testing stage is maintained at $15{ }^{\circ} \mathrm{C}$ using thermoelectric cooling. $\mathrm{Cw} L-I$ characteristics for a broad-stripe (100- $\mu$ m-wide $\times 2$-mm-long) facet-coated $(90 \% / 10 \%)$ device is shown in Fig. 4, indicating cw output powers up to $1.4 \mathrm{~W}$. This corresponds to a COMD power density level of $3.4 \mathrm{MW} / \mathrm{cm}^{2}$, assuming COMD occurs across the entire 100 $\mu \mathrm{m}$ facet. Recent results from similar Al-free active-region lasers emitting at the 800-nm-wavelength region show much higher COMD power density levels $\left(17.5 \mathrm{MW} / \mathrm{cm}^{2}\right)$ are possible from InGaAsP active-layer devices. ${ }^{4}$ The sudden failure observed here at power levels well below the expected maximum COMD indicates strong filamentation is occurring. In broad-stripe devices, filamentation leads to localized COMD, confirmed here by postmortem inspection. Thus, higher output powers can be expected by reducing filamentation through the use of smaller stripe widths, more efficient heat removal, and improved material uniformity. Fundamental transverse mode operation was confirmed by measuring the far-field distribution in the transverse direction. The full width at half maximum $\theta_{\perp}$, is $38^{\circ}$ and full width at $1 / e^{2}$ is $68^{\circ}$ over the whole range of drive current. These values are in very good agreement with the calculated fundamental transverse-mode far-field distribution, and indicate the second-order transverse mode is suppressed. Preliminary burn-in measurements performed at $50{ }^{\circ} \mathrm{C}(200 \mathrm{~mW}$ output power) for $50 \mathrm{hr}$ indicate no significant degradation. Longterm reliability measurements are planned in the future.

In conclusion, we have demonstrated 730-nm-emitting compressively strained InGaAsP quantum-well lasers with low internal loss $\left(\alpha_{i}=3 \mathrm{~cm}^{-1}\right)$, high $T_{0}(72 \mathrm{~K})$ and $T_{1}(153 \mathrm{~K})$, cw output powers of $1.4 \mathrm{~W}$, and stable fundamental transverse-mode operation from a broad-waveguide structure. Further improvements in performance can be achieved by optimizing the amount of the strain in the quantum well, and improving thermal management to reduce filamentation.

${ }^{1}$ P. L. Tihanyi, F. C. Jain, M. J. Robinson, J. E. Dixon, J. E. Williams, K. Meehan, M. S. O'Neill, L. S. Heath, and D. M. Beyea, IEEE Photonics Technol. Lett. 6, 775 (1994).

${ }^{2}$ M. A. Emanuel, J. A. Skidmore, M. Jansen, and R. Nabiev, IEEE Photonics Technol. Lett. 9, 1451 (1997).

${ }^{3}$ D. Z. Garbuzov, N. Yu. Antonishkis, A. D. Bondarev, A. B. Gulakov, S. N. Zhigulin, N. I. Katsavets, A. V. Kochergin, and E. V. Rafailov, IEEE J. Quantum Electron. QE-27, 1531 (1991).

${ }^{4}$ J. K. Wade, L. J. Mawst, D. Botez, R. F. Nabiev, M. Jansen, and J. A. Morris, Appl. Phys. Lett. 72, 4 (1998).

${ }^{5}$ D. P. Bour, D. W. Treat, K. J. Beernink, R. L. Thornton, T. L. Paoli, and R. D. Bringans, IEEE Photonics Technol. Lett. 6, 1283 (1994).

${ }^{6}$ D. F. Welch, W. Streifer, C. F. Schaus, S. Sun, and P. L. Gourley, Appl. Phys. Lett. 56, 10 (1990).

${ }^{7}$ P. J. A. Thijs, L. F. Tiemeijer, J. J. M. Binsma, and T. van Dongen, IEEE J. Quantum Electron. QE-30, 477 (1994).

${ }^{8}$ A. Mathur and P. Dapkus, IEEE J. Quantum Electron. QE-32, 223 (1996).

${ }^{9}$ L. J. Mawst, A. Bhattacharya, M. Nesnidal, J. Lopez, D. Botez, A. V. Syrbu, V. P. Iakovlev, G. I. Suruceanu, A. Z. Mereutza, M. Jansen, and R. F. Nabiev, Proceedings of the 8th International Conference on Metal Organic Vapour Phase Epitaxy 1996, Cardiff, Wales, U.K., June 9-13, 1996, [J. Cryst. Growth 170, 383 (1997)].

${ }^{10}$ J. Diaz, I. Eliashevich, K. Mobarhan, E. Kolev, L. J. Wang, D. Z. Garbuzov, and M. Razeghi, IEEE Photonics Technol. Lett. 6, 132 (1994).

${ }^{11}$ F. Daiminger, S. Heinemann, J. Nappi, M. Toivonen, and H. Asonen, CLEO Tech. Dig. Ser. 11, 482 (1997).

${ }^{12}$ L. J. Mawst, IEEE/OSA Conference on Lasers and Electro-Optics '97, Tech. Digest, Baltimore, MD, May 18-23 1997, 11, Paper CMA3.

${ }^{13}$ P. W. Mcilory, A. Kurobe, and Y. Uematsu, IEEE J. Quantum Electron. QE-21, 1958 (1985). 